\title{
Noch einmal über die Verwandten der ungarischen Sprache
}

LÁszló Hontr: Anyanyelvünk atyafiságáról és a nyelvrokonság ismérveiről. Tények és vágyak. [Über die Verwandtschaft unserer Muttersprache und die Merkmale der Sprachverwandtschaft. Fakten und Hoffnungen.] Budapest: Tinta könyvkiadó 2012.

Die Diskussion über die uralischen Wurzeln der ungarischen Sprache dauert in Ungarn weiterhin an. 2010 erschien in Budapest ein von László Honti, Sándor Csúcs und László Keresztes herausgegebenes Buch $^{1}$, das die Schriften behandelt, in denen die Verwandtschaft des Ungarischen mit den anderen uralischen Sprachen bestritten wird und alternative Theorien über die Herkunft des Ungarischen vorgestellt werden. Diese Publikation wurde auch in Band 61 (2012) der Finnisch-Ugrischen Forschungen besprochen. Nun hat László Honti das Thema erneut aufgegriffen und ein Werk verfasst, das eigehender über die verschiedenen unwissenschaftlichen Alternativtheorien berichtet. Es handelt sich jedoch nicht nur um eine Wiederholung des Bisherigen; Honti hebt neue Perspektiven hervor und bietet zugleich eine aktuelle Zusammenfassung der Diskussion über das Thema.

Das Buch gliedert sich in zwei Teile. Im ersten Teil (Kapitel 1-4) geht es um die Grundlagen der historisch-vergleichenden Sprachwissenschaft, und die Verwandtschaft des Ungarischen mit dem Chantischen und Mansischen wird gründlicher als bisher dargestellt. Honti präsentiert anhand der Belege des Uralischen Etymologischen Wörterbuchs die Quantität des gemeinsamen Wortschatzes dieser Sprachen, die gemeinsamen Lautveränderungen und morphologischen Elemente. So führt er Lesern, die nicht mit der Finnougristik vertraut sind, die Verwandtschaft zwischen dem Ungarischen, Chantischen und Mansischen vor Augen.

Im ersten Teil schreibt Honti auch über die Verwandtschaft der indogermanischen Sprachen. Er zieht einige Stammworte als Beispiele heran, vergleicht ihre Entsprechungen in den germanischen und slavischen Sprachen und erwähnt einige wichtige Lautveränderungen, die während der Sonderentwicklung dieser Sprachen 
eingetreten sind. Honti verwendet das indogermanische Beispiel als Parallele, mit der sich die uralische Sprachfamilie vergleichen lässt. Als nächstes führt er beispielhaft einige uralische Grundwörter an und erläutert die in ihnen auftretenden regelmäßigen Lautentsprechungen. Als Beispielsprachen dienen Finnisch und Ungarisch, und vorgestellt werden z.B. die regelmäßige Entsprechung der finnischugrischen wortanlautenden Klusile, die Entsprechung des $t$ zwischen Vokalen im Wortinlaut und die Denasalisierung im Ungarischen.

Im ersten Teil seines Buches stellt Honti die Grundlagen der Finnougristik klar verständlich dar und kann einen Leser, der sich dem Thema vorurteilslos und ohne Fanatismus nähert, sicherlich überzeugen. Der Text ist recht wissenschaftlich, setzt also beim Leser ein gewisses Bildungsniveau voraus. Er wird vermutlich nicht alle Dilettanten erreichen, die sich mit der Frage befassen. Es kann auch sein, dass die Anhänger der alternativen Theorien ohnehin schwer zu überzeugen sind, weil ihre Motive nicht im Studium der Grundlagen der historischen Sprachforschung liegen, wie im zweiten Teil deutlich wird. Im Epilog seines Buches vergleicht Honti denn auch den Konflikt zwischen der wissenschaftlichen Finnougristik und den alternativen Theorien mit dem unvereinbaren Widerspruch zwischen der Evolutionstheorie und dem Kreationismus.

Der zweite Teil (Kapitel 5 und 6) ist umfangreicher; hier stellt der Verfasser alternative Theorien vor und führt einen Diskurs zwischen ihnen und den wissenschaftlichen Quellen. Die Absicht ist, dem kritischen Leser Instrumente zu geben, anhand derer er sich eine Auffassung davon bilden kann, was bei der Argumentation zugunsten einer Sprachverwandtschaft glaubwürdig ist und was nicht. Mehrmals kommt zur Sprache, dass in weiten Kreisen immer noch Unklarheit darüber besteht, dass sprachliche und genetische Verwandtschaft sich nicht bedingen. Die sprachliche und genetische Herkunft des Volkes ist in Ungarn auch Teil der tagespolitischen Diskussion. Honti berichtet zum Beispiel von dem Julianus barát-Projekt, das Staatssekretär Géza Szőcs vorgeschlagen hat und das rege Diskussionen auslöste. Dieses Projekt hatte das Ziel, die finnisch-ugrische Sprachverwandtschaft mit den Mitteln der Genetik anzufechten oder sogar zu widerlegen.

Unter denjenigen, die alternative Theorien vorlegen, sind zahlreiche hoch gebildete Wissenschaftler. Daher kann man sich nur wundern über die fantasievol- 
len Behauptungen, denen zufolge das Ungarische bereits vor 40000 Jahren in Afrika gesprochen wurde oder mit bestimmten indianischen Sprachen verwandt sei. Einige dieser Autoren sind auch Kenner der historisch-vergleichenden Sprachwissenschaft, aber dennoch finden sich in ihren Werken erhebliche Fehler. Ein Kapitel für sich sind natürlich die Dilettanten, die aus den Erzählungen der Bibel Verbindungen zur uralischen Vergangenheit herstellen. Honti korrigiert diese Auffassungen in ausgesprochen unverblümtem Ton.

Das Buch bietet stellenweise eine äußerst unterhaltsame Lektüre. Den finnischen Leser amüsieren vor allem die Passagen, in denen die Verfechter alternativer Theorien die finnische Sprache, die Finnen und die Geschichte Finnlands kommentieren. Honti zitiert zum Beispiel die Auffassungen von Maria Die(t)rich (der Name wird schon in den Originalquellen auf zweierlei Weise geschrieben), denen zufolge im Jahre 1831 Satakunta, Suomi und Varsinais (sic!) gemeinsam ein Gebiet namens Turku-Pori bildeten, dessen zwölf Ortschaften sich 1997 auf sechs verringerten. Das Alte Finnland wiederum ist nach Ansicht der Autorin das Gebiet, in dem die Menschen (die Finnen?) während der schwedischen Herrschaft wohnten und das jetzt in Russisch- und Finnisch-Karelien geteilt ist. Finnland trennte sich bereit 1634 von Schweden, wurde aber erst 1809 an Russland angegliedert. Welchen Status hatte das Land in der dazwischen liegenden Zeit? Die Finnen als Volk sind ein Hunnenstamm, und schließlich kommt sogar der Wichtel aus der Burg zu Turku ins Spiel! Die Angaben stammen aus dem Buch A szumér-magyar kérdés megoldása, das im Verlag Fríg Kiadó erschienen ist. Dieser Verlag hat mehrere alternative Werke über die Vorzeit der Ungarn und des Ungarischen herausgebracht.

Einen Grund für den Vormarsch der alternativen Auffassungen sieht Honti im Zusammenbruch der Sowjetunion und der darauf folgenden Meinungs- und Redefreiheit. Die Nation muss nach dem Kommunismus ihre Identität und ihre Herkunft neu konstruieren. Man glaubt, die Sprache gebe unmittelbar Auskunft über den genetischen und kulturellen Ursprung des Volkes. Aus diesem Grund fällt es vielen schwer, die Verwandtschaft des Ungarischen mit den anderen uralischen Sprachen zu akzeptieren. Die heldenhaften Eroberer des Heimatlandes (fonfoglalók) waren europäischer Herkunft und keine Verwandten der Uralier, denn dann wären sie ja nur eine „lallende Affenhorde“ 
Noch einmal über dieVerwandten der ungarischen Sprache

gewesen, wie ein zitierter Vertreter Anmerkung

der alternativen Theorie schreibt.

Der Fischtran stinkt immer noch!

1. Honti László (Chefred.) - Csúcs Sándor - Keresztes László (Red.), A

Harri Mantila nyelvrokonságról. Az török, sumer és egyéb áfium ellen való orvosság. Budapest: Tinta könyvkiadó 2010. 